\title{
Religiosidade contemporânea brasileira: estilo de vida e reflexividade*
}

\author{
DeIS SiqueIRA**
}

\begin{abstract}
Resumo: O texto ancora-se, em particular, em uma pesquisa que está sendo desenvolvida há mais de dez anos sobre novas religiosidades, na UnB/ANPq. Este é um dos fenômenos mais instigantes do campo religioso brasileiro, ainda que quantitativamente insignificante, sobretudo se comparado com o crescimento do neqpentecostalismo. Embora as estratégias, as composições, em tomo do que seja "estilo de vida" sejam distintas, ensaia-se uma reflexão comparativa entre ambos, ancorada na relação inclusão/exclusão da modemidade, em um mundo cada vez mais gldbalizado. Nesse sentido, o eixo analítico enfatizado é a exigência crescente de um "eu reflexivo", tal como sugerido por Giddens.
\end{abstract}

Palavras-chave: religião, novas religiosidades, neo-pentecostalismo.

\section{Apresentação}

O dado mais provocativo do Censo Demográfico Brasileiro do IBGE (2000) é o que indica que os evangélicos ${ }^{1}$ compõem o grupo que mais cresceu na última década do século XX. ${ }^{2}$ Esta é, portanto, uma das chaves-mestras para pensar os elementos mais significativos da religiosidade brasileira na atualidade.

A heterogeneidade do grupo evangélico é marcante. ${ }^{3}$ Ele é fragmentado, não há uma unidade institucional, equivalente ao que há no catolicismo. Há uma diversidade organizacional,

\footnotetext{
* Texto resumido e modificado a partir do ensaio "Religiosidad contemporanea brasileña: mercado, médios, virtualidad y reflexividad", publicado em Desacatos. Revista de Antropologia Social, n. 18, México: mayo-agosto, 2005, p.87-102 (deissiqueira@yahoo.com.br).

** Pesquisadora do CNPq/Departamento de Sociologia da Universidade de Brasília. Coordenadora da Pesquisa sobre Novas/Alternativas Religiosidades desde 1994 (FAP-Df/ $\mathrm{CNPq} / \mathrm{UnB}$ ).

1. Instituto Brasileiro de Geografia e Estatística (IBGE). Na atualidade, no Brasil, há um consenso em torno de que todas as partições, denominações, igrejas, originadas do protestantismo europeu ou norte-americano, são chamadas de evangélicas. Protestantismo seria apenas uma referência histórica.
}

teológica e litúrgica que se evidencia nas muitas igrejas e denominações existentes no Brasil.

Essa segmentação pode ser explicada por vários fatores. Dentre outros, as várias Reformas européias (luterana, calvinista, anabatista) e que ecoaram, ainda que sutilmente, no Brasil (missionários que vieram da Europa); a diversidade étnica e cultural própria do país; o processo colonial de "sincretização" na religiosidade do Brasil ${ }^{4}$ o processo de modernização (destacando-se a migração massiva campo-cidade,

2. O Censo Demográfico Brasileiro de 1990 revelou a existência de 13.189 .283 evangélicos, cerca de $9 \%$ da população nacional. Já o Censo de 2000 mostrou a existência de 26.184 .942 evangélicos, o que representava $15,41 \%$ da população. A população evangélica praticamente dobrou em uma década. Segundo Freston (2001), o Brasil é hoje a maior comunidade evangélica do Terceiro Mundo, em termos absolutos, e a segunda do mundo, atrás apenas dos Estados Unidos.

3. Agradeço às contribuições, oferecidas com competência e criatividade, em particular sobre o neopentecostalismo, por Itelvides José de Morais, meu orientando de doutorado, no Departamento de Sociologia da Universidade de Brasília. Uma reflexão mais completa pode ser encontrada em seu projeto de tese, já aprovado, A ascensão do protestantismo pentecostal em Goiânia.

4. Destaquem-se aqui as reflexões de Sanchis (1995) sobre o sincretismo constituinte da sociedade brasileira. 
sobretudo a partir da década de 1950) e seus correspondentes ajustes às necessidades religiosas da população.

Atualmente, o grupo dos evangélicos pode ser dividido em três grandes ramificações. $\mathrm{O}$ primeiro ramo diz respeito aos chamados evangélicos independentes, históricos ou tradicionais: $32 \%$ do total dos fiéis. Entre eles, destacam-se os presbiterianos, os metodistas, os batistas tradicionais e os luteranos (Mafra, 2001; Mariano, 1999).

Mas, no conjunto dos evangélicos, destacase o segundo grupo, pentecostal. Dos um pouco mais de 26 milhões de evangélicos brasileiros, cerca de $68 \%$ se declararam pentecostais. O Brasil representa a maior comunidade pentecostal de todo o mundo (Assembléia de Deus, Congregação Cristã no Brasil, Igreja do Evangelho Quadrangular, O Brasil para Cristo, Deus é Amor). Assim, se pode falar de uma pentecostalização do protestantismo e de um desenraizamento da tradição religiosa, abrindo-se, crescentemente, para uma quebra da lealdade, simultânea à perda crescente da hegemonia católica.

A terceira vertente (ou "terceira onda") é a dos neopentecostais. Destacam-se as igrejas: Universal do Reino de Deus, Igreja Internacional da Graça de Deus, Renascer em Cristo e Sara Nossa Terra (fundadas, respectivamente, em 1977, 1980, 1986 e 1992-1994).

A partir de investigações realizadas por vários estudiosos (Oro, 1992; Mariano, 1999; Oro \& Semán, 2000; Freston, 2001), pode-se, sinteticamente, afirmar que se trata de igrejas autóctones (fundadas por brasileiros e com investimento nacional); têm fortes lideranças; opõem-se aos cultos afro-brasileiros; seus cultos estimulam a expressividade emocional; colocam ênfase em rituais de cura e exorcismo, ${ }^{5}$ na guerra espiritual e na prosperidade (Teologia da Prosperidade); são bastante liberadas no que toca a estereótipos de usos e de costumes; ${ }^{6}$ têm uma estruturação empresarial significativa, adotam técnicas de marketing e gerenciamento

5. Mesclando várias influências. Exemplos: do catolicismo, água abençoada, cruzes; dos cultos afro-brasileiros, sal grosso, arruda, exorcismo das entidades oriundas da umbanda do candomblé, em um movimento ambíguo de negá-las e "exorcizá-las". modernos, incluindo uma exploração agressiva dos meios de comunicação de massa e técnicas energéticas de persuasão, afinal, são "modernas" e "adaptadas" à realidade, o que é uma de suas mais fortes bandeiras de legitimação.

As igrejas neopentecostais cresceram na década de 1970. Na década seguinte, identificase a expansão do que se pode chamar de Igreja Eletrônica, marcada por lideranças bastante personalizadas e autônomas em relação às denominações cristãs tradicionais (Assmann, 1986). E é, sobretudo, a partir dos anos 90 do século passado, que o crescimento das chamadas igrejas pentecostais da "terceira onda" se fez mais evidente. Várias delas com projetos de crescimento ambiciosos em termos nacionais e internacionais (Mariano, 1999).

Simultanemante, na outra ponta das transformações recentes do campo religioso brasileiro, o outro movimento que chama bastante a atenção, juntamente com o crescimento do neopentecostalismo, é a expansão de uma religiosidade exótica, caracterizada, no geral, como parte de uma orientalização do Ocidente, mas que não se resume a isto, como não se restringe ao movimento New Age.

Em termos de números de adeptos, os dados censitários de 2000 nem permitem falar de crescimento. Os grupos místico-esotéricos que compõem a nebulosa esotérica (ou campo religioso ampliado, religião difusa, religiosidade flexível flutuante, espaço religioso ou novas forma do sagrado, nova sensibilidade místicoesotérica, esotérica-holista da New Age, novas formas de religião, crédulos difusos, nebulosa heterodoxa, religiões seculares, religiosidade inorgânica, nebulosa polivante da Nova Era, dentre muitas outras categorias que se encontram na literatura existente a respeito) são insignificantes no conjunto da população brasileira.

6. Em lugar de pastores que andavam com uma Bíblia surrada embaixo do braço e faziam pregações nas ruas, eles agora passam desapercebidos e fazem pregações, sobretudo em templos; nos cultos usavam palavras rebuscadas e citavam mais o Diabo do que o "Nosso Senhor Jesus Cristo". Hoje falam uma linguagem a mais acessível possível. Em lugar de arrebanhar fiéis nas periferias, continuam recrutando jovens nessas zonas urbanas, porém a ênfase está posta mais em programações culturais e passeios turísticos, praias, chácaras; em lugar de figurinos conservadores e cores neutras/ escuras, roupas atualizadas/modernas, coloridas. 
Mas o crescimento dos grupos místicoesotéricos é marcante na sociedade brasileira, e Brasília é cada vez mais conhecida como a capital místico-esotérica, ou capital do terceiro milênio. D. Bosco, um salesiano italiano, teve um sonho-premonição de que na região onde se construiu a capital do Brasil se construiria a capital do terceiro milênio, onde jorraria leite e mel.

Não obstante as manipulações políticas desse sonho, este vai se tornando lenda e esta se vai tecendo como representação social. Crescentemente, a capital vai se realizando como Cidade Mística. Ou seja, o mito vai se tornando lenda e esta realidade. E mesmo grupos místico-esotéricos que não tiveram nenhum sonho ou premonição para se instalar na região aqui têm de se fazer representar, afinal se trata da capital mística do país, capital do terceiro milênio, ou da região onde se localiza o chakra cardíaco do planeta. ${ }^{7}$

Tratarei, inicialmente, do que é mais significativo em termos dos dados do Censo Demográfico Brasileiro, o crescimento dos neopentecostais. E voltarei às novas religiosidades, na tentativa de uma reflexão comparativa.

Esta se centra em torno da crescente demanda por posicionamento/escolha/composição (reflexividade e estilo de vida) por parte do sujeito em relação à sua religiosidade. Para tanto, serão incorporados alguns dados sobre mídia, entretenimento, lazer, os quais servirão de sustento para a referida reflexão. Mas não serão, neste momento, privilegiados como objeto de estudo.

\section{Religião e Esfera Pública}

Nem todas as denominações evangélicas andam de braços dados com a política e com a mídia. Por exemplo, as testemunhas de Jeová e

\footnotetext{
7. O fato de que a maioria da população do D. Federal representa a capital e região como Cidade Mística (ainda que não seja o caso para a representação Cidade do Terceiro Milênio) foi confirmado por várias frentes de investigação. Uma discussão pontual sobre o assunto pode ser encontrada, por exemplo, em Siqueira e Bandeira: O profano e o sagrado na construção da "Terra Prometida" (1997) e em Misticismo no Planalto Central. A Chapada dos Veadeiros, o chakra cardíaco do planeta (1998).
}

os membros da Congregação Cristã no Brasil negam-se a atuar politicamente através do voto, ou mesmo a servir o Exército, por se ancorarem na tradição/separação radical entre religião e ação no mundo, mesmo tendo demonstrado forte crescimento nos últimos anos. ${ }^{8}$

Mas pentecostalismo e ação política costumam andar próximos. Esse segmento dos evangélicos parece ter, cada vez mais, a atuação política como um de seus pilares. A visibilidade pública do avanço da representação formal dos evangélicos no cenário político do Brasíl é incontestável. É, sobretudo, a partir dessa representação que se conseguem concessões de rádios, canais de televisão, além da aprovação de projetos, promulgação ou modificação de leis que permitam, dentre outros, que áreas públicas possam ser doadas para a construção de templos e que uma infra-esturura eletrônica de grande porte seja utilizada em alto volume (uma constante em seus eventos), ainda que haja uma legislação reguladora de poluição sonora.

Os vereadores, deputados estaduais e federais dessas denominações, eleitos em número cada vez maior, centralizam suas preocupaçoes em torno da defesa e da apresentação de projetos que venham ao encontro de interesses dos membros das denominações, pois são esses interesses os que mais parecem tê-los auxiliado em suas eleições. ${ }^{9}$

Como definiria Guerra (2002), igrejas são como empresas sociais cuja proposta é criar, manter e fornecer religião para um conjunto de indivíduos e, como instituições, desenvolvem interesses e lutam por eles. Por sua vez, nessa mesma direção, Chiavenato (1999) afirma que a igreja também é uma organização, visto que

\footnotetext{
8. Segundo o Censo Demográfico de 2000, a Congregação Cristã no Brasil foi a que mais cresceu entre as denominações que procuram se distanciar das ações políticas e da mídia via rádio, jornais e televisão. Ela teve um crescimento de $37,7 \%$ na última década do século, passando de 1,6 milhão de fiéis para 2,2 milhões.

9. É significativo que, no segundo turno das eleições presidenciais de 2002, ambos os candidatos se esforçaram, via mídia, em demonstrar o apoio da maioria das lideranças dos evangélicos brasileiros, tentando influenciar esses fiéis. No que toca à bancada evangélica, esta tinha 48 deputados em 2001. Cresceu em 25\% nas últimas eleições (outubro de 2002) e passou a ter 60 deputados, sendo 23 deles da Igreja Universal do Reino de Deus.
} 
são unidades sociais (ou agrupamentos humanos), intencionalmente construídos e reconstruídos a fim de atingir objetivos específicos.

No grupo das igrejas com atuação política mais constante, podem ser citadas a Igreja Universal do Reino de Deus e a Igreja Sara Nossa Terra, que também apresentaram crescimento numérico bastante similar ao da Igreja Apostólica Ministério Comunidade Cristã, a qual agrega, fortemente, crescimento numérico e atuação política. ${ }^{10}$

Não é demais lembrar, apoiados em Max Weber (1994 e 1967), que uma das características que marcam os líderes religiosos é justamente o seu carisma. Porém, este também é uma característica de políticos. E muitos pastores são um misto de sacerdotes e profetas. Não há uma barreira intransponível que demarque os momentos em que se deve estar preocupado com a fé e aqueles em que se deve estar preocupado com outros problemas sociais. Ainda que uma igreja possa ter como núcleo central a propagação da fé através de suas mensagens religiosas, de seus atos litúrgicos, de suas práticas pastorais, ela também defenderá, como instituição que é, outros interesses. Nesse sentido, é importante o seu número de sacerdotes e de seguidores, sua situação financeira, a troca que estabelece com os poderes constituídos, sua inserção no mundo das relações socioeconômicas, nas estruturas da sociedade envolvente.

Tanto assim que, a partir de uma investigação recentemente realizada com cem líderes de uma organização neopentecostal e cem líderes de uma tradicional, concluímos que eles estão imersos em um contexto de grande desgaste físico e mental, ritmo excessivo de trabalho e forte cobrança por resultados (ainda que indiquem altos níveis de prazer em seu trabalho).

As novas relações das organizações religiosas com a sociedade impõem novas estruturas, novos meios de gerenciar, novas tecnologias, aproximando-as (igrejas) de um modelo mais secularizado [...].

10. Entre 1990 e 2000, a Assembléia de Deus (a maior igreja evangélica brasileira) passou de 2,4 milhões para 4,5 milhões de membros (crescimento de quase 85\%). Nesse mesmo período, a Igreja Apostólica Ministério Comunidade Cristã passou de 3 mil para 200 mil adeptos.
[...] A preocupação constante com produtividade, eficiência e qualidade dos produtos oferecidos pelas organizações pesquisadas pode ser observada, por exemplo, na simplificação da mensagem com o objetivo de "conversão" de muitas pessoas, utilizando-se de vários meios de comunicação, tal como a mídia de massa. Além disso, se observa, nos discursos dos líderes, principalmente entre os neopentecostais, uma apropriação clara de aspectos típicos da realidade de mercado, tais como metas, células de produção, empreendimento, típicos de modelos empresariais modernos. (Silva e Siqueira, 2006, p. 3) ${ }^{11}$

Ou seja, as transformações atuais do mercado de trabalho acabam se refletindo também nas organizações religiosas. A nova cara do mercado de trabalho e das relações profissionais impõe uma série de instrumentos. "Esses também se refletem no âmbito das organizações religiosas a fim de maximizar uma relação ideal entre qualidade, produtividade e eficiência" (Silva e Siqueira, 2006, p.18).

Nessa direção, a afirmação de Fonseca, referindo-se à Igreja Universal do Reino de Deus, pode, certamente, ser generalizada, pelo menos para as igrejas neopentecostais

A "Evangelização na Mídia” é parte central do ser/fazer da igreja, a qual, conjuntamente, com a ação política, as campanhas, os grandes eventos, seus templos, e mais recentemente sua "preocupação social" [...] demarcam as principais características de uma igreja que pretende atingir um status similar ao experimentado pela Igreja Católica na sociedade brasileira. (Fonseca, 2003, p. 49)

Quem quer ter voz ativa e, entre outras coisas, conquistar mercados para seus produtos (e não se confinar em nichos, culturalmente encerrados), ocupando lugares no mercado da cultura, deve ter em mente não apenas o diálogo racional, mas também "jogar" com base nas regras do "novo jogo", que valoriza, crescentemente, a partir da atuação política, a imposição de pontos de vista. A luta por influência política incorpora, crescentemente, partidos, funcio-

11. Texto apresentado no VI Simpósio Internacional sobre Religiões, Religiosidades e Culturas, UFMS/Dourados - de 23 a 26 de abril de 2006. 
nários de alto escalão, ou de organizações com prestígio nacional ou internacional. E também se busca a adesão de líderes religiosos, artistas e demais "formadores de opinião" (Habermas, 1997).

Identifica-se, na atualidade, o esforço para demonstrar que projetos, os quais beneficiam diretamente os fiéis de uma determinada denominação ou das denominações evangélicas em geral, também são projetos legítimos e que são desejados por grande parcela da população. Assim como na esfera pública de Habermas, o convencimento é fundamental.

Há mais do que a permissão para cultos que utilizam parafernália eletrônica/sonora em jogo. A compra ou a manutenção de canais de televisão, a permissão para o registro ou o funcionamento de rádios e também de jornais, a transformação de um espaço público em templo passam pela relação com a política, já que é apenas o poder público que pode conceder a autorização para o funcionamento dessas emissoras de rádio e televisão.

Afinal, esta é a maneira que os demais grupos atuam na esfera política. A partir das reflexões de Habermas (2003), é possível perceber que, para que os pentecostais atinjam os objetivos políticos almejados, através de sua atuação nessa esfera, devem seguir, em primeiro lugar, as regras que nela imperam. A ação política nos moldes postos é a única ou a mais competente a ser praticada. Segundo esse autor, não há outra forma de atuação política acessível aos diversos segmentos sociais, incluindo aqui os evangélicos, que forneça resultados tão compensadores. Mesmo que, em muitos momentos, essa atuação possa estar em desacordo com valores propriamente religiosos.

A mídia eletrônica tem sido um dos aliados mais poderosos na construção do espaço dos evangélicos e, sobretudo, dos neopentecostais no Brasil. Assim, a mídia poderia ser pensada sobretudo como mercadoria (Fonseca, 2003). $\mathrm{Ou}$, a partir da tradição segundo a qual a mídia é definida, sobretudo, como cultura

[...] como um local de constituição de identidades e como um espaço para a configuração de comunidades [...] não é apenas um fenômeno econômico ou um instrumento político. Mais do que isso, a mídia deve ser estudada como um processo de criação de identidades culturais, fator central na constituição dos atores sociais e na produção e distribuição de bens simbólicos. (Fonseca, 2003, p. 34)

Bem, ela também pode ser pensada como mecanismo de apropriação da esfera pública.

\section{Religião, mercado e Evangelho da Prosperidade}

A articulação entre religião e mídia não é recente. O uso dela, entendida como "meios" (livros, revistas, jornais, rádio), ou seja, canais de transmissão, de difusão, pelo menos por parte do cristianismo, é antiga. Mas nos toca refletir sobre o movimento mais recente de mediatização, pensado, particularmente, em termos de uma imbricação de tecnologias computacionais e de telecomunicações da realidade e a uma simultânea virtualização do real. Refiro-me às teias, ou à rede que vem sendo costurada entre mídia e religião, ou vice-versa. Esse movimento incita diferentes atores sociais, com destaque para os evangélicos, e entre eles, os neopentescostais, a buscarem o controle de canais e de espaços da mídia.

Segundo Fonseca (2003), parece que no Brasil o uso evangélico da televisão tem origem mais na percepção de líderes dessas denominações, ou comunidades religiosas, da potencialidade dos meios de comunicação do que na inspiração ou cópia de modelos norte-americanos.

No final de 2003 existiam sete emissoras de televisão em funcionamento de propriedade de igrejas evangélicas: Igreja Universal do Reino de Deus, Assembléia de Deus, Igreja Internacional da Graça de Deus (que tem maior presença na mídia), Igreja Renascer, Sara Nossa Terra, Igreja Batista da Lagoinha. Uma vez mais se destacam as iniciativas da Igreja Universal do Reino de Deus - seu canal, a Record (comprada em 1990), é uma das principais emissoras abertas, com cobertura em quase todo o território nacional. $^{12}$

12. No Brasil, $87 \%$ dos lares têm TV e $90 \%$ têm rádio (Fonseca, 2003, p. 44). 
Além de emissoras de TV, começam a se consolidar empresas na área de comunicação que possuem nos evangélicos seu "target". As intenções também se movem para que nãoevangélicos venham a aderir a essas igrejas graças ao proselitismo, cada vez mais intenso, nesses meios. No primeiro semestre de 2000 os programas evangélicos de televisão representavam cerca de 80 horas semanais de veiculação [...] - em 1992 esse número não chegava a 45 horas. (Fonseca, 2003, p. 34)

Os programas tendem ao proselitismo, a ter um papel importante na cura, oferecer entretenimento ${ }^{13}$ e disseminar uma cultura evangélica que, além dos programas, conta com outras empresas na área de comunicação, tais como editoras, gravadoras, revistas.

[...] criando a oportunidade de uma intersecção entre religião e consumo sem precedentes [...]. As críticas em relação ao uso da mídia por parte de religiosos se baseiam geralmente em dois fatores: sua impessoalidade e seus altos custos. Analistas apontam esse uso como um dos principais reflexos da "mercantilização da fé", e, dentro da academia, as divergências com relação à "validade" dos meios de comunicação eletrônicos e da cultura de massas como uma linguagem específica são variados [...] a mídia é um espaço importante de veiculação de propaganda e venda e a Universal assumiu a concepção da religião como uma mercadoria, estabelecendo uma estrutura transnacional para viabilizar da melhor forma possível a exposição e a expansão de seu produto. (Fonseca, 2003, p. $45,47,49)$

A constituição de igrejas evangélicas como empresas, sobretudo as igrejas pentecostais da chamada "terceira onda" (neopentecostais), veio, simultaneamente, se evidenciando a partir das últimas décadas do século passado. Assim como as empresas capitalistas de produção de bens, elas procuram aumentar sua participação no mercado consumidor, utilizando-se de muitos componentes de racionalidade no sentido utili-

13. Segundo Fonseca (2003), a partir da investigação de dois shows de duas igrejas pentescostais, o Show da Fé (Igreja da Graça), e o Despertar da Fé (Igreja Universal do Reino de Deus), a ênfase comum é fornecer entretenimento para sua audiência. "Ocupar o tempo dos telespectadores" (Fonseca, 2003, p. 44). zado por Max Weber (1994) para alcançar o maior número de fiéis (espécie de consumidores) com o mínimo de esforço, o que não deixa de ser uma maneira de elevar sua participação no mercado religioso.

É dentro deste contexto que se pode melhor pensar a articulação religião-entretenimento. Também é, sobretudo a partir da década de 1980 , que a aventura, a viagem, o ócio se transmutam, no imaginário brasileiro, como turismo. E com o turismo se ressignificam as noções de lazer e de entretenimento, valorizadas, em particular, a partir da década anterior, pelo regime militar, dentro dos esforços de controlar e domesticar a força de trabalho. ${ }^{14}$ Inserir-se na "onda do turismo" é uma outra forma de busca de legitimação dessas denominações, via "igreja moderna".

Também Meyer (2003), pensando a expansão do pentecostalismo em Gana, a partir de meados dos anos 80 e sua articulação com o cinema popular local, sugere que, agindo na esfera da diversão, os videofilmes, focalizando o consumo, popularizam o pentecostalismo, mais além das igrejas.

A nova conformação da religião como mercadoria possibilita uma maior presença dela no espaço público. Presença que, ao mesmo tempo, se concretiza, se visibiliza, como entretenimento. Afinal, enquanto tal, logra reunir grandes públicos, em espaços físicos grandiosos (estádios, antigas salas de teatro ou cinema), estimulando o surgimento de comunidades de sentimento, que não se esgotam na membresia, bem mais estrita, que caracterizava as denominações evangélicas até a década de 1960 ou 1970.

Dá-se um deslocamento da experiência religiosa para o espaço-ambiente da mídia. Penso, em particular, no público que freqüenta eventos, cerimônias, na forma de "programas religiosos" e que não necessariamente são fiéis de uma denominação em particular nem tampouco freqüentadores dos tradicionais cultos personalizados das igrejas, dos templos, os locais clássicos do "culto". Burity diria:

14. Consultar SIQUEIRA, D. Turismo e religiosidade em Brasília. In: MONTORO, T. S. (Org.) Cultura do turismo. Desafios e práticas sócio-ambientais. Brasília: Thesaurus, 2003. 
O sagrado encontra-se com a espectralidade do mundo virtual [...] espiritualidade espetacular, performática, voltada para e exibidora das grandes massas, feita de muita luz, som, música e figuras "carismáticas" [...] e transmitida de várias maneiras pela velha e nova mídia. (2003, p. 85)

Um outro elemento impõe-se como central para a análise da relação existente entre a religiosidade atual, a política, o mercado e a virtualidade e, concomitantemente, a conformação do pentecostalismo brasileiro, sobretudo o da "terceira onda": é o Evangelho ou a Teologia da Prosperidade - Deus deseja que seus filhos gozem a vida antes de morrer. É como se fosse possível construir um paraíso ainda na Terra.

O futuro é agora: o reino dos céus está ao alcance do desejo de todos os consumidores. Assim, o sucesso material/financeiro e a ascensão social passam a ser benções divinas. É por isto que o consumo se torna central na vida dos fiéis, como se ele passasse a ser construído, ancorado em valores centrais da religião, como fiéis/consumidores, reorquestrando o lugar do consumo na articulação entre modernidade e religião cristã. ${ }^{15}$

Pode-se afirmar que no Brasil se construiu um mercado de religiões, caracterizado por uma forte concorrência entre as suas denominações, as quais oferecem seus serviços religiosos, marcados por muita cura e milagre, como mercadorias a seus fiéis, tratados como consumidores e clientes. Até aqui, nenhuma novidade. $\mathrm{O}$ elo de ligação sobre o qual pretendo refletir diz respeito à articulação entre as promessas da modernidade e as posturas/relações com ela estabelecidas por parte da população (crítica, resistência, incorporação).

15. A complexidade do conceito de modernidade e suas derivações (pós-modenidade, modernidade tardia, modernidade moderna, alta modernidade, pós-tradicionalidade, modernidades cumulativas, modernidade moderna, modernidade reflexiva), assim como outros conceitos articulados a essa discussão (hibridação, sincretismo, convencionalização, des-territorialização), não será aqui desenvolvida. Estou apenas pressupondo a aceleração do processo de globalização e enfatizando, como se explicitará à frente, a reflexão em torno da reflexidade.

\section{Religião, cibercultura e virtualidade: 0 eterno retorno do numinoso}

Quando se pensa em mídia, tem-se de admitir que o real é crescentemente produzido, mesclando cada vez mais o material e o simbólico.

Seguindo pistas oferecidas por Derrida, Burity (2003, p. 80) diz que há algumas características centrais, que passam por nossa experiência de atualidade, marcada profundamente pela mídia. Essa cola, simultaneamente, o real aparente e o real virtual, o fato e a invenção.

Afinal, a realidade não está dada, é continuamente produzida e performaticamente interpretada. Conforme Derrida, quando um jornalista ou um político aparece na televisão, falando diretamente para cada um de nós, ele está, na verdade, lendo um texto que foi produzido em outro lugar, em uma situação distinta, possivelmente por outra pessoa ou por um grupo de pessoas, talvez anônimo.

Assim, identificam-se uma dimensão de síntese artificial (imagens, vozes sintéticas) da realidade e uma dimensão de virtualidade. A partir da tecnologia digital, reforça-se a virtualidade, ou seja, imagens virtuais, espaços, resultados e acontecimentos virtuais. Essa virtualidade afeta tanto o tempo quanto o espaço de imagens, de discursos, de notícias, de informação, que nos conectam com a atualidade. Nesta, vivencia-se um modelo referenciado no digital e no virtual, em lugar do modelo societário baseado na maquinaria e na indústria. Os mecanismos dão lugar a um padrão ancorado em fluxos e virtualidades.

Retornamos ao misterioso ou ao numinoso. Difícil não admitir o caráter religioso/misterioso dessa conexão entre real e virtual, propiciada pela tecnologia, pela cultura cibernética. Porque nos enfrentamos com forças extraordinárias, em boa medida, incompreensíveis para a maioria dos mortais, e que sobre ela exercem controle e poder também extraordinários. Ao mesmo tempo em que a mídia estaria a serviço dos homens, está acima dos mortais, como algo que "tudo vê".

Machado, investigando trabalhos realizados por intelectuais, chefes de laboratórios de universidades, sociólogos, filósofos, encontra muitas categorias religiosas e conclui que estes 
[...] “apresentam" o ciberespaço em tons proféticos e mágicos e, assim, realimentam o senso comum a respeito dos processos evolutivos da ciência, que são capazes de comprovar as verdades últimas de certos princípios de fé. (2003, p. 140)

E as pessoas que navegam no ciberespaço

[...] o vêem como uma dimensão sagrada; uma gama de informações que se devidamente acessadas e manipuladas conduzem a uma outra "dimensão" existencial e simbólica; o ciberespaço apresenta virtudes religiosas (no sentido clássico de religião); conectar-se no ciberespaço é ter a experiência de uma revelação de um outro mundo, de uma irrupção do sagrado em plena luz do quotidiano. (Machado, 2003, p. 140)

Esse autor pergunta-se então qual seria a relação entre tecnologia e religião.

Segundo ele, pode-se falar em uma cosmologia religiosa da virtualidade. Ou mesmo de uma cosmologia ciber-religiosa nos autores que discutem as novas tecnologias, a cibercultura e o ciberespaço. Pois se identifica uma articulação recorrente entre religião e tecnologia digital, feita tanto por aqueles que são os construtores do ciberespaço (engenheiros, informáticos), assim como por aqueles que os analisam. Ele levanta a hipótese de que talvez nossa fascinação por computadores seja mais espiritual do que utilitária.

Machado explicita o paradoxo: por um lado, a religião se tecnifica e, por outro, a ciência se encanta.

O que nos interessa perceber é como, em todas as versões desta relação entre ciência e religião, a realidade ciber é naturalizada, e deste modo possibilita a emergência de um novo campo de profecias, relacionado a novos modelos de vida social. (Machado, 2003, p. 134)

Afinal, os teóricos do ciberespaço não deixam de ser profetas de uma eternidade possivelmente alcançável através da evolução científica e tecnológica levada a seus últimos termos, tanto assim que a possibilidade da imortalidade se apresenta, a partir dela, ainda que seus princípios se encontrem, desde sempre, ancorados em uma dimensão religiosa. Os autores por ele visitados tanto analisam quanto prescrevem. $\mathrm{O}$ autor enfatiza a articulação das profecias ao potencial agregador do ciberespaço para a sociedade contemporânea. Deduz que, ao mesmo tempo em que os autores anunciam o fim da religião, a profetizam, em outros termos. Daí nasce o novo enigma: quais outros termos são esses, no contexto que estamos tratando, de elaboração do ciberespaço?

Bem, a virtualidade pode ser definida, dialeticamente pensando, em termos de uma oposição ao real, assim como de uma ampliação dele.

A virtualidade é percebida [...] como uma oposição favorável para a análise de aspectos que muitas vezes passam desapercebidas na configuração da trama social, conduzindo a uma reflexão sobre as fronteiras e o hibridismo entre estas categorias: real e virtual [...]. A noção de virtualidade, reanimada pela cultura ciber, aumentou o seu campo de aplicação, virou um instrumento apropriado para definir estas esferas imateriais fortes na vida humana: os sonhos, a religião e agora o próprio ciberespaço. Esta relação entre a virtualidade cibernética do ciberespaço e a virtualidade clássica [...] da religião configura-se como uma interessante chave de análise para a intimidade entre estas esferas encontradas nos autores analisados. (Machado, 2003, p. 143)

Segundo esse autor, o conceito de virtual, além de conceder um estatuto ao imaterial, orienta os questionamentos sobre a própria realidade do que aprendemos a conceber como real da cultura. Afinal, dá-se uma interconexão entre o sagrado e o profano: a circulação mágica de informações e a trivialidade do cotidiano. Navegar no ciberespaço não deixa de ser uma forma de experienciar um outro mundo, como se o sagrado invadisse ou ocupasse o cotidiano. Porque parece que há uma idealização do ciberespaço como um paraíso de liberdade e se identifica uma percepção da racionalidade comunicacional como o melhor dos mundos possíveis (Sodré, 2003). E isso diz respeito tanto aos seguidores de religiões tradicionais quanto os das novas religiosidades.

A transcendência e o mistério cobram, uma vez mais, seu status, ainda que em novos termos. 
Em um lugar-momento onde seria de se esperar, por excelência, a ausência da transcendência, ela retorna, de um mundo misterioso e mágico, e nada esquecido.

Afinal, como diria Giddens (2002, p. 10), o eixo ou a ordem da modernidade hoje, por ele chamada de alta ou modernidade tardia, é póstradicional, mas isto não quer dizer que as certezas da tradição e do hábito tenham sido substituídas, de todo, pelas certezas do conhecimento racional.

Talvez, então, valha a pena considerar a leitura do conceito weberiano de secularização, sobretudo como processo societário de diferenciação e separação das esferas (sociais, culturais, institucionais), como o faz Pierucci (1998). Porque a secularização continua. Não se pode abandonar esse conceito central da sociologia, mas de fato, estamos, simultaneamente, diante de um processo de reencantamento do mundo ou, pelo menos, de pensar que a secularização não significou, necessariamente, desencantamento do mundo. O que instiga questões interessantes para quem reflete sobre a dimensão religiosa da condição humana atualizada em tempos atuais, denominado de pós-modernidade, ou como seja.

\section{Reflexividade: neopentecostais lidando com a exclusão}

A aceleração da globalização tem exacerbado o não-cumprimento das inúmeras promessas da modernidade para parcelas cada vez maiores de países como o Brasil. Juras emancipatórias baseadas na instrumentalidade da técnica, e em um poder fantástico da razão e da ciência de construir um mundo desnudo de mistério, livre dos poderes inenarráveis da natureza. E da religião. Mas a globalização recente impõe contradições cotidianas entre a inclusão prometida e desejada e a exclusão, cotidianamente vivenciada nas esferas materiais, econômicas, sociais, culturais.

\section{Como diria Burity}

E em todas as modalidades de meio (mídia) que imaginamos é absolutamente central a orientação de mercado, lançando mão de todos os recursos - tecnológicos, do marketing e da administração - para promover produtos de todos os tipos imagináveis, em escala planetária, e contribuindo decisivamente para consolidar a hegemonia de uma cultura de consumo e de uma visão estetizante do sujeito e do mundo em todos os circuitos "formais" da vida social mundialmente [...] a mídia emergiu ao longo desta expansão da modernidade e serve-lhe cada vez mais de habitação (ethos) [...] os meios articulam, promovem e difundem valores de uma cultura de massas, ainda quando transmitem discursos críticos da ordem vigente. (2003, p. $81,89)$

O discurso neopentescostal centraliza o consumo, como já foi dito (o Evangelho da Prosperidade). Assim, o sucesso material acaba funcionando como um equalizador imaginário (Meyer, 2003): o consumo pode permitir que as pessoas se tornem uma classe para si mesmas, apesar das diferenças abissais presentes nos espaços de produção e distribuição dos bens, tanto em nível nacional quanto internacional. $\mathrm{E}$, nesse processo, o papel da mídia, tal como orquestrado pelo pentecostalismo, parece que vem sendo vertebral.

Parcelas significativas da população, em todo, ou quase todo o mundo ocidental, decepcionadas pelo não-cumprimento das promessas da modernidade, parecem se agarrar às promessas do pentecostalismo, ancoradas em mágicas de acesso ao consumo, via entrega a Deus, a Jesus Cristo, ao Espírito Santo, e tentam encontrar nessa religião um mensageiro possível de prosperidade. Como diria Meyer (2003, p. 28), referindo-se a Gana: "o pentecostalismo seria um [...] guia confiável para tratar da globalização".

Nessa direção, vale recuperar uma questão importante (Burity, 2003; Sodré, 2003): haveria um vínculo entre religião e mídia, em que se constrói um discurso moral sobre o mundo, no qual o dever seria assumido pela própria mídia, a partir de uma fala autoprofética de si mesma. Afinal, consumo e moralidade passam a se equivaler (o futuro - o reino dos céus, aqui e agora). Essa lógica mercantil moralizante fundiria o comportamento de mercado, o individualismo e a chegada do futuro.

Segundo Burity, 
[...] o papel de mediação cultural e de trabalho sobre a subjetividade que classicamente tem sido realizada pela religião passa crescentemente a ser terreno da intervenção da moralidade midiática. Entre o "desconhecido" das estruturas e processos sociais, políticos, econômicos, culturais, que se revestem de crescente complexidade, e a consciência e linguagem popular, mais afeita a mecanismos simplificadores de formação de opinião e de gosto, os meios circulam, promovem e difundem valores de uma cultura de consumo e de massas, ainda quando transmitem discursos críticos da ordem vigente. (2003, p. 86)

Mas essa afirmação merece considerações. Até a década de 1960 ou 1970, um evangélico era facilmente reconhecido por sua conduta, seus trajes, por sua postura, por sua maneira de carregar a Bíblia. As proibições eram imensas e precisas aos membros das denominações. A membresia inscrevia-se em seu corpo, além de seus comportamentos e práticas. Na atualidade, é difícil distinguir um pentescostal, sobretudo um neopentescostal, de fiéis de outras religiões ou mesmo de não-fiéis, ou ateus, espiritualistas ou sem religião. A tradição perde, ${ }^{16}$ crescentemente, seu domínio. Daí Giddens (2002) falar em ordem pós-tradicional ou modernidade tardia.

Porque, simultaneamente, na construção da conduta tal como trabalhada por Weber, mesmo entre os neopentescostais, aumenta a referência em torno do indivíduo em termos de seu autocontrole permanente, em prejuízo da percepção anterior como um vaso a ser ocupado por Deus ou pelo Diabo. Ou, como diria Giddens (2002, p. 12), “[...] a auto-identidade se torna um empreendimento reflexivamente organizado".

Assim, segundo ele,

16. Segundo Giddens (2001), por um lado, a modernidade destrói a tradição, mas, por outro, haveria uma certa interlocução entre ambas ("tradição na modernidade"). Assim, a questão do que seria uma sociedade tradicional permanece complexa, de difícil solução, e uma das poucas afirmações que se pode fazer é de que se trata daquela onde a tradição tem um papel significativo. De qualquer forma, não se pode aqui destrinchar essa discussão. Apenas enfatizo, ainda concordando com esse autor, o caráter ritualístico/normativo/ moral da tradição (verdade formular/acessada por poucos/ guardiões/ segurança aos que se vinculam a uma tradição). Ou seja, destaco, no momento, a diminuição da tradição em relação à múltipla escolha pessoal. o projeto reflexivo do eu se dá dentro de um contexto de múltipla escolha, que é filtrada, continuamente, por sistemas abstratos, num movimento dialético com os processos de padronização, sobretudo devido à mercantilização geral da vida. [...] quanto mais a vida diária é reconstruída em termos do jogo dialético entre o local e o global, tanto mais os indivíduos são forçados a escolher um estilo de vida a partir de uma diversidade de opções. (Giddens, 2002,p. 13)

Afinal, a cultura atual é uma cultura de risco, e a aferição de risco contém muitos imponderáveis. A modernidade passa a ser cada vez mais "experimental", mais desafiadora, porque mais perigosa (Giddens, 2001, 2002).

A religiosidade contemporânea, além de seu vínculo mais estreito com o consumo, é marcada pela experimentação, singular em relação ao processo de adesão à religião que a regeu desde finais do século XIX até meados do século XX (Carvalho, 1994).

Assim, segundo Sanchis (1995), identificase na atualidade uma pluralização das opções religiosas e dos estilos de crença e pertencimento, a qual também ocorre dentro das grandes tradições religiosas, como é o caso do catolicismo e do protestantismo. Há um trânsito entre a tradição católica/afro-brasileira e as religiosidades ancoradas na escolha individual. Há uma lógica moderna/atual na forma como o discurso dos católicos carismáticos, por exemplo, enfatiza a escolha individual e pessoal como um princípio fundamental da experiência religiosa.

Nesse sentido, vale incorporar as contribuições de Meyer (2003, p. 22), estudando o fenômeno em Gana: o poder exterior (possessão, Diabo, maus espíritos) não é descartado, mas cresce a responsabilidade pessoal do fiel. Refere-se aos regimes pentecostais de subjetividade e de tecnologias do eu, celebrados como garantia mais adequada do sucesso individual.

Afinal, pode-se pensar em um materialismo idealizado, que agrega mercado, individualismo e o futuro já, mas que seria moralmente controlado: o sucesso material é abençoado, mas a modernidade tem suas tentações e seduções.

A maioria dos videofilmes atualmente produzidos em Gana afirma a necessidade de 
adotar a religiosidade pentescostal para poder se envolver com a modernidade de modo seguro e disciplinado. Essas indicações sobre Gana se casam com as investigações realizadas por Oosterbaan (2003) sobre pentecostais no Rio de Janeiro.

Ele sugere como a cultura visual pentecostal não se define apenas pelo programas televisivos a que os fiéis querem assistir, mas também por aqueles programas a que eles não querem assistir. Assistir à TV se referencia em um movimento de atração e de rejeição, seja de imagens, seja de narrativas, tocando ao fiel a cautela, a seleção, o enfrentamento de situações que sejam chamativas, mas não conformes aos ensinamentos da Bíblia, cobrindo os olhos, em alguns momentos, por exemplo. Meyer enfatiza a "reflexão interior" e Oosterbaan o "estar atento ao corpo", afinal o ser humano também é carne, e o Espírito Santo pode abandonar o corpo de um fiel, onde ele deve habitar.

A ambivalência está posta. Por um lado, a busca de legitimação, afinal se trata de uma igreja "moderna/atual", tal como esclarece um pastor neopentecostal em uma entrevista recente: ${ }^{17}$ ele pode falar gírias, freqüentar academias, e até pode tomar algo de álcool nos finais de semana: “[...] não podemos ficar fora deste universo [universo próprio dos jovens do mundo moderno atual]. [...] Voltar a vida para o Senhor não é mais sinônimo de religião. Virou estilo de vida".

Por outro lado, há o espaço, inevitável, da subjetividade de cada um. Porque, simultaneamente, como afirma, na mesma reportagem jornalística acima citada, o presidente do Conselho de Pastores de Igrejas Evangélicas: "Nós nunca abriremos totalmente as portas da igreja para o mundo".

As fronteiras entre o profano e o sagrado, diferenciação vertebral para alguns sociólogos, como Durkheim, por exemplo, estão postas, crescentemente, aos próprios fiéis pentecostais, o que é, por sua vez, um ponto de entrada para os que buscam uma nova religiosidade, não ancorada em uma única verdade, em um único dogma, em uma única verdade, em um único Senhor.

17. Entrevista concedida por um pastor da Igreja Sara Nossa Terra ao jornal Correio Braziliense, 17-10-2004.
Uma ética, crescentemente construída pelo sujeito, pela subjetividade. Porque também muitas outras fronteiras da sociedade moderna, ancoradas em polaridades excludentes, estão balançadas. Cada vez mais cobra seu status o lugar da subjetividade, do eu reflexivo de que nos fala Giddens (2002), incluindo, crescentemente, evangélicos, que têm de decidir, crescente e cotidianamente, entre o certo e o errado, entre o correto e o incorreto, ainda que estes continuem, de alguma maneira, referenciados em Deus e no Diabo, polaridade que anda, de fato, em franca decadência.

Afinal, como lembra esse autor, apesar de que diferenças de classe, de gênero, de raças ou de etnias implicarem diferentes acessos a bens materiais e simbólicos, também os excluídos, os marginalizados tratam de construir um estilo de vida, porque este também se refere a decisões que são tomadas, mesmo em condições severas de privação.

Bem, o pentecostalismo cresce, sobretudo, entre aqueles que são, em princípio, excluídos da sociedade, com problemas básicos, como é o desemprego em nossas sociedades. ${ }^{18}$

E o que dizer dos adeptos dos grupos místico-esotéricos, ou buscadores de uma nova religiosidade, os quais conformam o outro ponto do contínuo que inclui, sobretudo, adeptos que têm níveis altos de escolaridade e, no geral, a materialidade resolvida? ${ }^{19}$

\section{Reflexividade: buscadores de uma nova religiosidade lidando com a inclusão}

Os adeptos das novas religiosidades são pessoas que buscam uma forma de vivenciar uma religiosidade que seja anti-hierárquica, antidogmática, anti, extra ou para-eclesial. Tanto assim que se autodenominam centro, escola, grupo, legião, filosofia. Isto porque não se

\footnotetext{
18. Registre-se que o avanço dos neopentecostais tem se dado não apenas em áreas urbanas, mas também em pequenas cidades e em regiões "de fronteira". No mapa religioso brasileiro, a região que apresenta os maiores índices de diversidade religiosa é a do Acre, de Rondônia e entorno.

19. Consultar SIQUEIRA, D. As novas religiosidades no Ocidente. Brasília, cidade mística. Brasília: Editora da Universidade de Brasília, 2003; SIQUEIRA, D. e LIMA, R. B. de. Sociologia das adesões. Novas religiosidades e a busca místico-esotérica do Brasil. Rio de Janeiro: Garamond, 2003.
} 
admitem como religião. E, se o fazem, esse aspecto é secundário. Mesmo religiões anteriores ao cristianismo, como é o caso do(s) budismo(s), vivenciadas como uma filosofia ou um estilo de vida: uma nova forma de vivenciar a religiosidade.

Eles tendem ao holismo e ao ecumenismo; não se restringem à ancoragem de um único mestre, um ser superior ou iluminado, porque transitam entre eles: Buda, Cristo, Hare Krishna, Bahay'u'lá, S. Germain, Maitreya, outros líderes que tiveram sua revelação ou iluminação na Amazônia, através de enteógenos indígenas, de pessoas que se iluminaram durante a construção da capital brasileira, tais como Tia Neiva, uma caminhoneira, que criou o Vale do Amanhecer, ou o Mestre Yucanaan, que aí criou a Cidade Eclética.

Talvez o fenômeno mais instigante do processo seja o fato de haver muitos buscadores, os quais, depois de transitarem por vários grupos, constroem sua religiosidade por conta própria. Uma bricolagem religiosa, incorporando práticas, crenças de várias fontes, incluindo as cristãs.

Centrados em valores tais como "o divino encontra-se em cada um de nós; há que se desenvolvê-lo", insistem na possibilidade quase perdida, pelo processo de socialização (persona) e pelos valores hegemônicos da sociedade atual (ancorada, por excelência, em um consumismo ilusório), de se conectar com o "Eu maior", o "Eu divino", o "Eu crístico". Daí, inclusive, a identificação da articulação tão próxima desses buscadores com as práticas alternativas ou nãoconvencionais (homeopatia, ioga, florais, mapa astral, tarô, meditação, alimentos orgânicos, medicina preventiva e não curativa). Porque as convencionais trazem a marca da visão de mundo e dos valores da sociedade moderna (destrutiva, consumista, curativa e não preventiva, baseada na fragmentação e não no holismo, em uma ciência tecnicista e autoritária).

Há que se diminuir, secundarizar, ou mesmo anular o ego e construir um novo estilo de vida, que não priorize a monetarização, a mercantilização, a destruição da vida, características da sociedade envolvente. Essa busca chega a incluir pessoas que, no limite, admitem viver sem se alimentar, nutrindo-se vivendo "de luz", do que se vê, do que se ouve, se cheira, em um estado contemplativo/meditativo permanente.

Quais seriam os pontos de conexão que podem nos permitir pensar, simultaneamente, nos dois pontos do continuum, os mais excluídos e os menos excluídos? Para além dessas diferenças, defrontamo-nos com algo em comum: a subjetividade e a reflexidade. A individualidade moderna levada às suas últimas conseqüências, impondo a exigência de um "eu reflexivo", para os mais incluídos e para os mais excluídos da modernidade na atualidade.

\section{Incursões sociológicas quase conclusivas}

Por um lado, no Brasil, chama a atenção o crescimento dos evangélicos, e, sobretudo, dos neopentecostais, tanto em termos numéricos quanto na mídia, na esfera pública, na representatividade política, mesclando mídia, consumo, prosperidade, profano e sagrado. Mais além da religião, uma religiosidade que continua a ser âncora de atribuição de sentido à vida, de resolução dos dramas cotidianos, da maioria dos pobres, dos excluídos da sociedade brasileira.

Por outro lado, os buscadores de uma nova religiosidade anticlerical, anti-institucional, que são, sobretudo, pessoas com a materialidade resolvida, com alto nível de escolaridade e de renda, enfim, em sua maioria, incluídos, com acesso aos escassos bens materiais e simbólicos da modernidade atual.

Os primeiros, pentecostais, ancorados na Teologia da Prosperidade. Modernos, por excelência. Já não são protestantes. Não protestam: são evangélicos. Caso protestem, é porque se trata de um luta pela inclusão. Tanto usam a mídia, a esfera e os cargos públicos, as gírias, os roteiros turísticos, enfim, o que a sociedade atual oferece, crescentemente, para construir sua legitimidade e inclusão na sociedade envolvente. Sem abandonar a certeza da palavra e da vida de Cristo. O Evangelho da Bíblia segue sendo o eixo e, sobretudo, o sofrimento de Cristo, por e para todos os humanos.

Os segundos, buscadores de uma nova religiosidade, ecumênicos, almejando o desapego da materialidade, da ilusão consumista, dos dogmas, dos poderes institucionais e de suas ultrapassadas práticas de representatividade 
política hegemônicas (sindicato, partidos políticos). "Eliminar o sofrimento da condição humana", como proposto pela disciplina espiritual do Buda.

Um novo estilo de vida ancorado em práticas alternativas, ou não-convencionais. Trata-se aqui de fugir, como se pode, de tudo que é hegemônico: da mídia, dos apelos do consumo, dos fast foods, da revista Playboy.

Mas ambos falam de um novo estilo de vida. De que estilos de vida? Muito distintos, à primeira vista. Mas a referência continua sendo a centralidade da sociedade ancorada na mercantilização e na monetarização da vida, estilos de vida marcados, sobretudo, pela inclusão ou pela fuga dos valores hegemônicos da sociedade. No caso dos neopentecostais, pela inclusão (a partir do evangelho de Cristo). Para os buscadores de uma nova religiosidade, ecumênica, pelo distanciamento dos valores e práticas básicos da modernidade, ainda que não se possa falar de exclusão/negação.

$\mathrm{O}$ eixo de ambas parece espelhar posicionamentos diante de um processo acelerado de globalização. Aqui não se pode mover a partir da polaridade inclusão-exclusão. Porque ambos os movimentos são mediados pelo sujeito, o indivíduo que deve julgar, avaliar, escolher, eleger, subjetividades compondo "estilos de vida".

Marx morreu, o muro de Berlim caiu. Mas a sociedade capitalista, crescentemente excludente, marginalizadora, criadora de diferenças, continua bastante viva. Uma nova etapa da globalização, e mais capitalista que nunca. $\mathrm{Na}$ atualidade, podemos observar, a partir das duas tendências religiosas mais significativas e em princípio, opostas, muito distintas, em um país de Terceiro Mundo, como a religião nos conta de nosso tempo ocidental.

É que a religiosidade, mais além da religião, sempre conteve surpresas. Afinal, historicamente, foi a religiosidade a maior responsável pela mediação cultural e pelo trabalho sobre a subjetividade. Mas a sociologia tendeu a privilegiar a sua dimensão institucional, a Igreja. Assim, permitimos que a piedade, a caridade, a dádiva fossem entregues à teologia, como se não fossem constituintes de nossas relações sociais cotidianas.
Nós, cientistas sociais, não podemos mais perder tempo. A religiosidade, essa dimensão constituinte da condição humana (busca pelo numinoso, pelo misterioso, pelo sagrado, pelo transcendental), pode ser acoplada, mas não subordinada, a outro estruturante da condição humana. Agrupadas, as pessoas (o homem é um ser gregário) são atores sociais, que tendem a construir regras, hierarquias, relações assimétricas de poder. Enfim, instituições.

A busca por uma nova religiosidade (anticlerical, anti-institucional) é um fenômeno crescente, pelo menos, no Ocidente. Mesmo no Japão, as religiões que mais crescem depois da Segunda Guerra Mundial são desse tipo. Enfrentar esse movimento de mão dupla, o qual inclui, por um lado, busca por inclusão e, por outro, crítica/resistência (ainda que não negação) da modernidade atual me parece central às ciências sociais. Ou deveria ser, sobretudo para intelectuais que se movem a partir dos movimentos/ contradições/ambigüidades.

Espero ter contribuído para essa reflexão.

\begin{abstract}
The text is based, in particular, in a research that it's being developed for over ten year about new religiosities at UnB/APq. This is one of the most instigating phenomena in the brazilian religious field, even though quantitatively insignificant, if compared to the growth of neo-Pentecostalism. Although the strategies, the compositions, arround of what is "life style" are distinct. It is estimated a comparative reflection between both, based on the relation inclusion/exclusion of modernity in a way more gldbalized world.

This way, the emphasized analytical axis its the increasing demand of a "reflexive self", as sugested by Giddens.
\end{abstract}

Key-words: religion, new religiosities, neo-pentecostalism.

\section{Referências}

ASSMANN, H. A igreja eletrônica e seu impacto na América Latina. Petrópolis: Vozes, 1986.

BURITY, J. A. Mídia e religião: regimes do real entre o mistério, o aparente e o virtual. Religião \& Sociedade, 23(02), Rio de Janeiro: Iser, 2003.

CARVALHO, J. J. O encontro de velhas e novas religiões: esboço de uma teoria dos estilos de espiritualidade. In: MOREIRA, Alberto \& ZICMAN, 
Reneé (Orgs.) Misticismo e novas religiões. Petrópolis: Vozes, 1994.

CHIAVENATO, I. Administração de recursos humanos. São Paulo: Atlas, 1999.

FONSECA, A. Fé na tela: características e ênfase de duas estratégias evangélicas na televisão. Religião \& Sociedade, 23(02). Rio de Janeiro: Iser, 2003.

FRESTON, P. C. Evangelicals and politics in Africa, Asia and Latin America. Cambridge: Cambridge University Press, 2001.

GIDDENS, Anthony. Em defesa da sociologia. São Paulo: Editora Unesp, 2001.

Zahar, 2002.

Modernidade e identidade. Rio de Janeiro:

GUERRA, L. A metáfora do mercado e a abordagem sociológica da religião. Religião e Sociedade, 22(2). Rio de Janeiro: Iser, 2002.

HABERMAS, J. Direito e democracia entre a facticidade e validade. Rio de Janeiro: Tempo Brasileiro, 1997.

Mudança estrutural da esfera pública. 2. ed. Rio de Janeiro: Biblioteca Tempo Universitário, 2003.

MACHADO, C. Religião na cibercultura: navegando entre novos ícones e antigos comandos. Religião \& Sociedade, 23 (02), Rio de Janeiro: Iser, 2003.

MAFRA, C. Os evangélicos. Rio de Janeiro: Zahar, 2001.

MARIANO, R. Neopentecostais: a sociologia do novo pentecostalismo. São Paulo: Loyola, 1999.

MEYER, B. Pentecostalismo, prosperidade e cinema popular em Gana. Religião \& Sociedade, 23 (02). Rio de Janeiro: Iser, 2003.

OOSTERBAAN, M. Escrito pelo Diabo. Religião \& Sociedade, 23 (02). Rio de Janeiro: Iser, 2003.

ORO, A. P. Podem passar a sacolinha: Um estudo sobre as representações do dinheiro no neopentecostalismo. Cadernos de Antropologia, 9, (7). São Paulo, 1992.

; SEMÁN, P. Pentecostalism in the Southern Cone Countries - Overview and perspectives. International Sociology, 15 (4), 2000.
PIERUCCI, A. F. Secularização em Max Weber. Da contemporânea serventia de voltarmos a acessar aquele velho sentido. Revista Brasileira de Ciências Sociais, 13 (37). São Paulo: Anpocs, 1998.

SANCHIS, P. O Campo religioso será ainda o campo das religiões? In: HOORNAERT, E. (Org.) História da Igreja na América Latina e no Caribe. Petrópolis: Vozes, 1995.

Modernidade e Pós-modernidade. Análise \& Conjuntura, Belo Horizonte, v. 7, n. 2 e 3, mai./ dez., 1992.

SILVA, R. R., SIQUEIRA, D. Espiritualidade no trabalho e vivência de prazer-sofrimento em líderes religiosos. Revista Psicologia: Teoria e Pesquisa, UnB/Instituto de Psicologia, 2006. [No prelo].

SIQUEIRA, D. As novas religiosidades no Ocidente. Brasília, cidade mística. Brasília: Editora da Universidade de Brasília, 2003.

Turismo e religiosidade em Brasília. Cultura do turismo. In: MONTORO, T. S. (Org). Desafios e práticas socioambientais. Brasília: Thesaurus, 2003.

; LIMA, R. B. de (Orgs.). Sociologia das adesões. Novas religiosidades e a busca místicoesotérica do Brasil. Rio de Janeiro: Garamond, 2003.

; BANDEIRA, L. M. O profano e o sagrado na construção da "Terra Prometida". In: NUNES, B. F. (Org.). Brasília: a construção do cotidiano. Brasília: Paralelo 15, 1997.

Misticismo no Planalto Central. A Chapada dos Veadeiros, o chakra cardíaco do planeta. In: GOULART, L. M., et al. (Orgs.). Tristes Cerrados. Sociedade e biodiversidade. Brasília: Paralelo 15, 1998.

SODRÉ, M. Antropológica do espelho: uma teoria da comunicação linear e em rede. Petrópolis: Vozes, 2003.

WEBER, M. Sociologia da religião. In: Economia e sociedade. Brasília: Editora da Universidade de Brasília, 1994.

A política como vocação. In: Ciência e política. Duas vocações. São Paulo: Cultrix, 1967.

Ensaios de sociologia. Rio de Janeiro: Koogan, 1982. 